\begin{tabular}{|c|c|}
\hline & $\begin{array}{l}\text { International Journal of Trend in Scientific } \\
\text { Research and Development (IJTSRD) }\end{array}$ \\
\hline $\begin{array}{lll} & \\
0\end{array}$ & International Open Access Journal \\
\hline 00 & ISSN No: 2456 - 6470 | www.ijtsrd.com | Volume - 2 | Issue -3 \\
\hline
\end{tabular}

\title{
Impact of talent management practices on employee retention with respect to selected private hospitals in Sangli City
}

\author{
Mr. Suhas Shankarrao Jadhav \\ Assistant Professor, V.P. Institute of Management \\ Studies and Research, Sangli, Maharashtra, India
}

\section{ABSTRACT}

This study was about studying the impact of talent management practices on employee retention with respect to selected private hospitals in Sangli city. The objectives of the study were ;To study the current practices of talent management adapted for employee retention by selected hospitals in study area ,to study the relationship between talent management, employee turnover, employee retention practices in selected hospitals in study area. To achieve this, a sample of 23 respondents in the 4-private hospitals was selected. 23 employees from various designations were picked using simple random sampling from each private hospital. Questionnaires were administered to these employees over the period of study. Chi-square test was used to establish the relationship between talent management practices and employee retention that influenced them to continue in the same hospital. The Chi-square value that was obtained at $95 \%$ confidence level revealed that there is significant relationship between talent management practices and employee retention strategies in selected hospitals in study area. The findings can be used by private hospital owners to identify talent management practices required for retaining talented employees in the hospitals. The research could also be used to strategize how to modify the retention strategies to meet employees' expectations, gain their loyalty and improve overall satisfaction.

Keywords: Talent management, employee retention, employee satisfaction, employee turnover

\section{LITERATURE REVIEW:}

1. Yona Sakaja Mangusho, Raphael Kipkoech Murei (2015),

The researchers have conducted a research on "Evaluation of Talent Management on Employees Performance in Beverage Industry: A Case of Delmonte Kenya Limited", talent management practice within organization is an international human resource strategy that seeks to identify, develop, deploy and retain talented and high potential employees. The objectives of the study were to determine the effect of talent retention on employees' performance, assess how talent attraction impacts, effect of learning and development on employees performance in beverage industry in Kenya. The study adopted a descriptive research design in which the target population of 2,500 employees of Del Monte Kenya. The study used stratified sampling method to select 83 employees according to their job cadres. Descriptive statistics such as the standard deviation, percentages and frequency distribution were used. The study established that the job retention motivated the employees of Del Monte leading to ultimate performance. The study recommended that the management should ensure the work environment was attractive to the employees so as to motivate, thus leading to better performance.

2. Victor Oladapo, (2014).

The researcher has studied on" THE IMPACT OF TALENT MANAGEMENT ON RETENTION'His study sought to understand the challenges and successes of talent management programs and the reasons why some American companies choose not to have a program. This study also tested the predictive 
power of job security, compensation and opportunity on retention rates.

The data in this study found that for the organizations sampled with a talent management program $(69 \%$ of those studied), participants overwhelmingly recognized the strategic value often effective talent management program despite significant challenges to implementation. Participants cited opportunity for job advancement as the most significant factor affecting retention rate. For the organizations sampled without a talent management program (the remaining $31 \%$ of those studied), while nearly all HR managers' support talent management, the primary reason given for the lack of a program is the absence of executive management support. The study further revealed that job security, compensation, and opportunity for advancement were not found to have predictive value for employee retention rates. The current study was exploratory and descriptive in nature, and therefore helped to define some of the parameters and patterns of the perceptions of HR personnel regarding what matters in employee retention. The current study does not directly assess all of the potential factors relevant to employee retention, but uses the preconceived ideas of the researcher.

\section{Ali Chitsaz-Isfahani, HamidReza Boustani (2014).}

The researchers had conducted research on" Effects of Talent Management on Employees Retention: The Mediate Effect of Organizational Trust" Talent management is found to be important for modern organizations because of the advent of the Modern economy, new generations entering the human resource and the need for businesses to become more strategic and competitive, which implies new ways of managing resource and human capital. In this research they had investigated the relationship between Talent management, employee Retention and organizational trust. The aim of the article is to examine the effect of Talent management on employee Retention through organizational trust among staffs of Isfahan University in Iran. The research method is a descriptive survey. The statistical population consists of staffs of Isfahan University in Iran. The sample included 280 employees, which were selected randomly. Data have been collected by a researcherdeveloped questionnaire and sampling has been done through census and analyzed using SPSS and AMOS software. The validity of the instrument was achieved through content validity and the reliability through
Cronbach Alpha. The results of hypothesis testing indicate that there is a significant relationship between Talent management, employee Retention and organizational trust. The study is significant in that it draws attention to the effects of talent management on organizational trust and employees Retention in organization. The limitation of this study was it just aimed on six dimensions including Career Management, Mentoring, Coaching, Training, Job Experience and Succession Planning on employee Retention through organizational trust among staffs of Isfahan University in Iran. While other comprehensive dimensions were not covered

\section{Maya M., R. Thamilselvan (2013),}

The researcher had performed a study on "Impact of Talent Management on Employee Performance and Organizational Efficiency In ITSP's with reference to Chennai City", in his study addresses how talent management practices help in improving the performance of employees and its role in organizational efficiency. The survey was carried out on ITSP's in Chennai city. NASSCOM ranked top 5 companies were chosen and the samples were selected from the software development group, where job hopping behavior is very high. The data were analyzed using chi square test and Friedman analysis. The result showed a significant association on the role played by talent management in employee's performance and organizational efficiency. This study was restricted to only top 5 Information Technology Service Provider companies and hence the researcher does not have the knowledge about rest of the low performing companies.

5. Usha Tiwari, Devanshi Shrivastava, (2013)

The researchers had conducted a study on "Strategies And Practices Of Talent Management And Their Impact On Employee Retention And Effectiveness." They had studied the strategies and practices of talent management and their impact on employee retention and effectiveness of its execution at AREVA T\&D India Ltd. The prime focus of this study has to analysis the talent management initiative taken by the HR professional and find out the effectiveness of such initiatives as well as the satisfaction level of the employees. Simple percentage analysis, Chi squire test and analysis of variance (ANOVA) were used for evaluation. The study revealed that age of employees is independent from satisfaction but experience of employees does affect the satisfaction with the practices of talent management. Finding of ANOVA 
revealed that each of the parameter has a different impact on effectiveness of talent management practices but a distinctive impact on employee's satisfaction.

\section{Kwenin D. O., Muathe S., Nzulwa R.,(2013) The} researchers had worked on "The influence of employee rewards, human resource policies and job satisfaction on the retention of employees in Vodafone Ghana ltd." The purpose of their study was to investigate the influence of employee rewards, job satisfaction and human resource policies on employee retention in Vodafone Ghana ltd. The study surveyed 120 employees from Vodafone Ghana ltd. Data collection was done by means of a semi structured questionnaire through personal contacts. Data was analyzed with descriptive statistic and Pearson Chisquare. The result showed that when organization's reward systems are adequate, it does not only lead to equity, but increase retention. It was also found that job satisfaction and favorable human resource policies have positive link with retention. A limitation of the study was that the questionnaire was voluntarily completed by the respondents; the researcher there for had no information about non respondents.

7. Akila R. (2012) The researcher had carried a research on "A study on employee retention among executives at BGR energy systems ltd. Chennai”. The employee retention programme at BGR was not found satisfactory. The analysis of data revealed that employees have give highest weighting to comfortableness in working hours and not satisfied with the annual increments provided. Gender has significant relationship with work life balance. Correlation between job satisfaction and working condition leads to employee retention. The departments also have an influence on it. The factors that had a greater influence on employee retention were career opportunities, work life balance and recognition at BGR energy.

\section{Richard C. Hoffmana* and Frank M. Shippera,} (2011) The researchers hadengaged a study on "The impact of managerial skills on employee outcomes: a cross cultural study"Leaders with global skills are in demand by MNCs. Global management skills depend on the applicability of management practices across cultures. Using data from managers in 50 countries, this study examines the interaction effect of cultural values and managerial skills on two outcomes, employees' attitudes and workgroup effectiveness.
The results indicate that cultural values tend to have a greater effect when a manager is less skilled than when the manager is highly skilled. When the manager is highly skilled, the interaction effects of culture tend to disappear. The practical and research implications of these findings are discussed.

9. Anappindi S. and Manohar M.S. (2011) The researchers conducted a study on "I am here to stay ! The stock broking way (an Indian perspective) : part 1."

This study focused on how better one can integrate the employee aspirations with the goals and missions of an organization. The factors like changing office dynamics, grown intellectuality and aspiration etc. were studied for employee retention.

10. Ghosh Koustab and Sahney S. (2011) The researchers had studied the "Impact of organizational socio-technical system on managerial retention - A general liner modeling approach.'This study concluded that in the industrial organizations, designing the managerial jobs by balancing the both organizational social and technical subsystem elements does impact on managerial retentions.

11. Groeneveld S. (2010) The researcher conducted a research on a research on "Diversity and employee turnover in Dutch Public sector" to explore the differences in turnover and turnover intensions by gender and ethnicity. By analyzing the two data sets :determinants of turnover and turnover intension of both native Dutch and ethnic minority men and women, the results showed that the women's turnover is mostly commonly associated with the intrinsic factors (like needs and values etc.), where as for the men the causes are extrinsic factors (like organizational leadership, management support etc.)

12. Makawatsakul Nantapron and Kleiner $\mathbf{H}$. Brain (2010) The researchers had conducted a research on " the effect of downsizing on morale and attrition"They have studied the factors of morale and downsizing, how morale is measured. The study revealed the importance of role of management towards effective downsizing $\&$ positive attrition i.e. keeping the downsized employee happy during the downsizing process.

13. Bergiel E. B., Nguyen V.Q. and Clenney B. F. (2009) The researchers had studied "Human resource practices, job embeddedness and intention to quit" 
They used job embeddedness, a new construct, to investigate its mediation effect on its relationship between employees' intention to leave and four areas of human resource practices : compensation, supervisor support, growth opportunity and training. The results showed that job embeddedness fully mediated compensation and growth opportunity, partially mediated supervisor support, and did not mediated training in relation to employee's intention to quit.

14. Beulen Erik (2009) The researcher conducted study on " Contribution global service provider's Human Resource Information System (HIRS) to staff retention in immerging markets- Comparing issues and implications in six developing countries." The argument was illustrated by quotes from 16 semistructured expert interviews with Accenture HR executives and managers in Argentina, Brazil, China, India, Latvia and Slovakia. It was found that HRISs contribute positively to staff retention for global IT service providers in immerging markets. Especially important in minimizing the turnover is the support that they can provide for allocation of employees for international engagements, including scheduling and training. Culture and local labor market differences do of course influence the HR functionalities needed. This study provides insight into the factors that nesseciates local adaption to a global HRIS.

15. Cordray Kevin (2005) The researcher had conducted a research on "High retention rates bring customer benefits at SITEL- Direct- Why Call center company bucks the trend." The researcher found that the company consistently maintains monthly retention rates that are not only above the industry benchmarks but also compare well with other sectors in the customer services industry. The researcher further found the company's overall offering of comprehensive training, career development opportunities, working hour flexibility, sense of community and convenient location not only contribute to its strong position in the market place, but also to the experience of every customer interaction.

\section{Statement of the Problem:}

The hospitals being the part of service sector are largely dependent for their success and survival on the performance of human resource. This need makes the hospitals to recruit talented and skilled employees. But the real struggle of the hospitals just begins here.
As recruiting and selecting the skilled, talented staff is not just enough. The hospitals also need to retain them for long term. This process requires them to search continuously for the next skill set required within the staff for the competitiveness and then upgrading those skill sets on continuous basis. This eventually leads to skill management practices where negligence is observed in most hospitals due to various reasons and then it becomes one of the reasons for employee turnover. Secondly even the hospitals manage the skills of the employees then again there lies a risk of loosing the talented staff. The hospitals need to first define the talent precisely and then need to manage it within every human resource function. Failing to do this the hospitals can face the problem of loosing the talent which can be very costly affaire to the hospitals. In the light of above discussion the researcher has proposed a study entitled as "Impact of talent management practices on employee retention with respect to selected private hospitals in Sangli City."

\section{Objectives of the Study:}

1. To study the current practices of talent management adapted for employee retention by selected private hospitals in study area.

2. To study the relationship between talent management practices and employee retention in selected private hospitals in study area.

3. To draw the conclusion and suggest appropriate remedies, if required.

\section{HYPOTHESES:}

H0: "There is no significant relationship between talent management practices and employee retention in selected private hospitals in study area."

H1: "There is significant relationship between talent management practices and employee retention in selected private hospitals in study area."

\section{SAMPLE SIZE:}

The study targeted 23 respondents from 4 private hospitals in full operation in Sangli City during the period of research. Out of 25 well established more than 50 bedded hospitals, 4 private hospitals were selected. The respondents to participate in the research were selected using the random sampling procedure. 23employees were picked using random sampling from each hospital .This 23employees are selectedin the combination as 5 doctors, 10 nursing staff and 8 ward representatives. 
International Journal of Trend in Scientific Research and Development (IJTSRD) ISSN: 2456-6470

STATISTICAL TOOLS AND TECHNIQUES From the observed frequencies, the expected USED:

frequencies were calculated using the formula;

A questionnaire was used to collect data. The study incorporated data analysis tools, which included descriptive and inferential statistics to analyze the data collected. Chi-square test was used to establish the relationship between satisfaction about talent management practices and employee retention.

Expected frequency (E) = Row total X Column total/ Grand total

Table 3 illustrate the $\chi^{2}$ values calculated for using the Chi-Square formula-

$\chi^{2}=\Sigma\left(\mathbf{O}_{\mathrm{ij}}-\mathbf{E}_{\mathrm{ij}}\right)^{2} / \mathbf{E}_{\mathrm{ij}}$

DATA ANALYSIS, FINDINGS AND DISCUSSIONS:

Table No1 Satisfaction about talent management practices*Job continuation

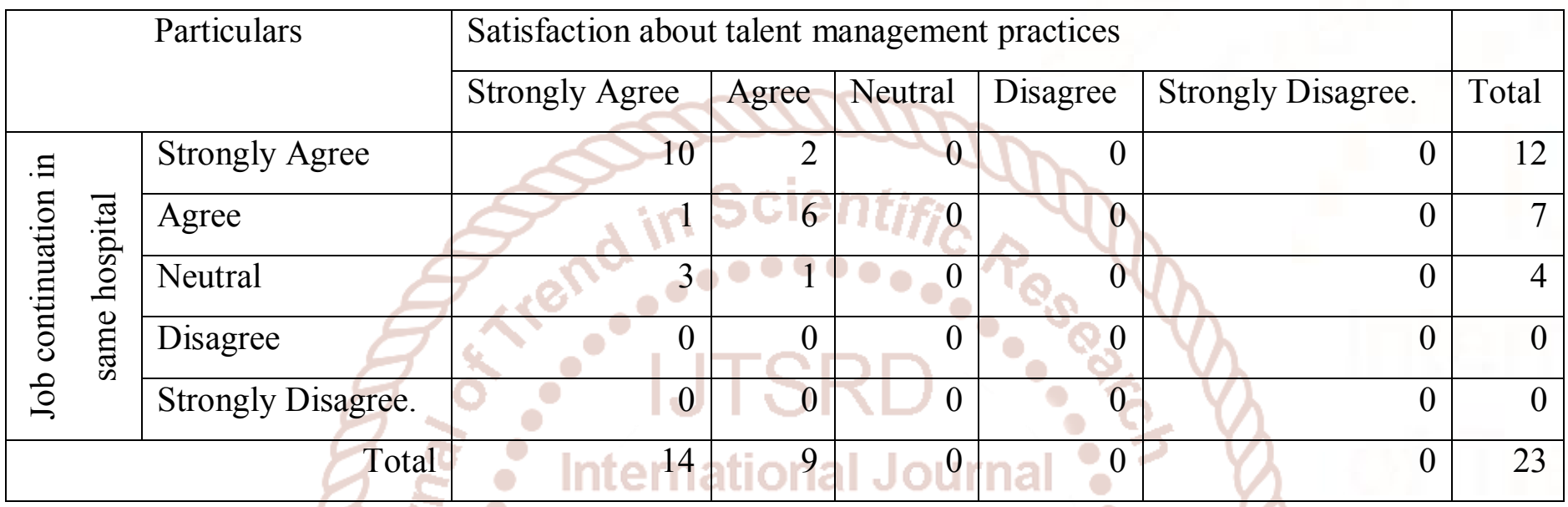

By applying pulling technique, the above table is reduced as follow to apply CHI-SQUARE test.

Table no.2 Satisfaction about talent management practices*Job continuation

\begin{tabular}{|c|c|c|c|c|}
\hline \multirow{2}{*}{\multicolumn{2}{|c|}{ Particulars }} & Satisfaction abo & management practices & \multirow[b]{2}{*}{ Total } \\
\hline & & Strongly Agree & Agree 70 & \\
\hline \multirow{3}{*}{ م. } & Strongly Agree & 10 & 2 & 12 \\
\hline & Agree & & 6 & 7 \\
\hline & Neutral & & 1 & 4 \\
\hline \multicolumn{2}{|l|}{ Total } & 14 & & 23 \\
\hline
\end{tabular}

Source- Primary Survey

The study analyzed the significance of the factors to establish their relation to satisfaction about talent management practices and employee retention; $\chi^{2}$ value was computed.

\begin{tabular}{|c|c|c|}
\hline \multicolumn{3}{|c|}{ Table 3 : Chi Square test } \\
\hline Chi Square value (p) & 9.49 & \multirow{4}{*}{$\begin{array}{l}\text { As 'p' value is greater than table value, hypothesis } \\
\text { H0 i.e. "There is no significant relationship between } \\
\text { talent management practices and employee retention } \\
\text { in selected private hospitals in study area."is } \\
\text { rejected. }\end{array}$} \\
\hline $\begin{array}{l}\text { Degree of Freedom } \\
\text { (df) }\end{array}$ & 2 & \\
\hline Level of Significance & $95 \%$ & \\
\hline Table value & 5.99 & \\
\hline
\end{tabular}


Hence H1: "There is significant relationship between talent management practices and employee retention in selected private hospitals in study area." is accepted.

\section{FINDINGS}

1. It is identified that most of the hospitals take very less efforts to acquire, develop and retain the talent.

2. Even some of the hospitals are conducting the talent management practices but the frequency of these activities is negligible.

3. It was found that talent development opportunities were provided to few staff in the hospital.

4. Employee's talent needs are also less considered while developing and implementing the talent development activities.

5. Even after completion of such talent development activities the employees are less considered for higher responsibilities and for the pay hikes.

\section{CONCLUSION}

It is concluded from the study that majority of the employees prefer hospitals for different reasons than just the remuneration. So, the private hospital owners have to take steps to retain the employees by not only proving them with good remunerations but also they have to provide ample talent development activities and they have to consider their talent needs while designing these activities. These hospitals have to increase the frequency of such talent development activities and link them with their promotional strategies. As the talented employees now a days prove to be good assets to the organizations.

\section{RECOMMENDATIONS}

1. The private hospitals have to take the talent management practices seriously and should not implement the just for the sake as it has a direct impact on talent retention. If these hospitals loose talented employees then the quality of services provided by the hospital and goodwill of the hospital remains on the stake.

2. Before designing the talent management practices the talent needs of the employees should be assessed very carefully. Failing to do this the success of talent management activities will remain questionable.

3. The hospitals should increase the frequency of such talent development activities and should relate it with employee promotional strategies after assessing their consequent performances.
4. As far as possible the hospitals should provide equal talent development opportunities to all staff even taking the cost factor into consideration. As the talented employees can provide better services and are able to increase the goodwill of the hospitals, fetching them more customers.

\section{REFERENCES}

1. Yona Sakaja Mangusho, Raphael Kipkoech Murei, (2015). Evaluation of Talent Management on Employees Performance in Beverage Industry: A Case of Delmonte Kenya Limited, International Journal of Humanities and Social Science, Vol. 5, No. 8; pp-191-199.

2. Victor Oladapo (2014), The Impact Of Talent Management On Retention, Journal of Business Studies Quarterly, Volume 5, Number 3, pp-1936

3. Ali Chitsaz-Isfahani, HamidReza Boustani (Sep 2014) , Effects of Talent Management on Employees Retention: The Mediate Effect of Organizational Trust, International Journal of Academic Research in Economics and Management Sciences, Vol. 3, No. 5,pp-114-128

4. Maya M., R. Thamilselvan (July-December, 2013), Impact Of Talent Management On Employee Performance And Organizational Efficiency. In ITSP's- With Reference To Chennai City, IJER, Vol. 10, No. 2, pp. 453-461

5. Dr. Usha Tiwari, Devanshi Shrivastava (October 2013), Strategies And Practices Of Talent Management And Their Impact On Employee Retention And Effectiveness, The International Journal of Management, Vol.2, Issue: 4, pp 1-10.

6. Kwenin D. O., Muathe S., Nzulwa R. (2013) , The influence of employee rewards, human resource policies and job satisfaction on the retention of employees in Vodafone Ghana ltd, European Journal of Business and Management,Vol.5,No.12,

7. Akila R. (September 2012), A study on employee retention among executives at BGR energy systems ltd. Chennai, International Journal Of Marketing, Finance services and Market research,Vol.1,Issue 9. 
8. Richard C. Hoffmana* \& Frank M. Shippera (2011), The impact of managerial skills on employee outcomes: a cross cultural study, The International Journal of Human Resource Management, 1-22, iFirst, Online article.

9. Anappindi S. and Manohar M.S. (2011), "I am here to stay ! The stock broking way (an Indian perspective): part 1." Industrial and commercial training, Vol 43, No.5, pp 297-306.

10. Ghosh Koustab and Sahney S. (2011), Impact of organizational socio-technical system on managerial retention - A general liner modeling approach., Journal of Modeling in Management,Vol.6,No.1,pp 35-59.

11. Groeneveld Sandra (2010), Diversity and employee turnover in the Dutch Public sector, International Journal of public sector management, Vol.24,No.6, pp594-612.

12. Makawatsakul Nantapron and Kleiner H. Brain (2010), The effect of downsizing on morale and attrition, Management research news,Vol.26, No.2/3/4,2003,pp52-62.

13. Bergiel E. B., Nguyen V.Q. and Clenney B. F.(2009) , Human resource practices, job embeddedness and intention to quit, Management Research News, Vol.32,No.3,2009,pp 205-219.

14. Beulen Erik (2009), Contribution global service provider's Human Resource Information System (HIRS) to staff retention in immerging marketsComparing issues and implications in six developing countries., Information technology and people, Vol.22.No.3,2009,pp 270-288.

15. Cordray Kevin (2005), High retention rates bring customer benefits at SITEL- Direct- Why Call center company bucks the trend., Human resource management International digest,Vol.13,No.4,2005,pp23-25. 